\title{
KAJIAN KUAT LENTUR BETON DENGAN MENGGUNAKAN Sika Concrete Refair Mortar SEBAGAI PENGGANTI SEMEN PADA CAMPURAN BETON K 300
}

\author{
ASRULLAH \\ Program Studi Teknik Sipil Fakultas Teknik Universitas Palembang \\ Jalan Dharmapala No.1A Bukit Besar Palembang 30139 \\ e-mail : asrull66@yahoo.co.id
}

\begin{abstract}
Abstrak
Sika Concrete Refair Mortar berpungsi sebagai komponen semen grouting untuk memperbaiki beton yang keropos dan juga untuk pengisi celah atau lubang-lubang seperti pada kolom baja, angkur baut dan sebaginya. Dalam penelitian ini peneliti mencoba pemakaian Sika Concrete Refair Mortar sebagai pengganti semen dalam beton dengan berbagai variasi campuran dari kebutuhan berat semen yang ditinjau dari kuat lentur beton. Metode rancangan campuran beton digunakan adalah SNI 03-2834-2000, sedangkan dalam pengujian kuat lentur digunakan metode SNI 4431:2011. Mutu beton yang digunakan adalah K 300 dengan benda uji berukuran 15 x15x60 cm. Penambahan Sika Concrete Refair Mortar sebagai pengganti semen sebesar 5\%, 10\%, 15\% dan $20 \%$ dari berat semen. Uji kuat lentur dilakukan pada umur beton 28 hari. Dari hasil pengujian maka dapat disimpulkan bahwa kuat lentur beton tanpa penambahan Sika Concrete Refair Mortar utama sebesar $53,84 \mathrm{~kg} / \mathrm{cm}^{2}$,

sedangkan kuat lentur terbesar dari penambahan Sika Concrete Refair Mortar terjadi penambahan Sika Concrete Refair Mortar 5\% dengan nilai kuat tekan 57,87 kg/cm2.
\end{abstract}

Keywords: Kuat Lentur, Sika Concrete Refair Mortar, K 300

\section{LATAR BELAKANG}

Beton merupakan bagian dari konstruksi yang mempunyai peranan penting dalam pembangunan. Beton adalah campuran semen, agregat halus (pasir) dan agregat kasar (kerikil/split) serta ditambahkan bahan tambahan yang bervariasi [1]

Sika Concrete Refair Mortar berpungsi sebagai komponen semen grouting.untuk memperbaii beton yang keropos dan juga untuk pengisi celah atau lubang-lubang seperti pada kolom baja,angkur baut dan sebaginya. Adapun keunggulannya adalah siap pakai dan mudah di aplikasikasikan, tidak susut, mudah mengalir, kekentalan bisa di atur sesuai konsumsi air, dan kekuatan mekanis tinggi [13]. Penelitian yang pernah dilakukan tentang kuat lentur diantaranya, Yohanes Trian Dady 2015, hasil penelitiannya menunjukkan bahwa semakin tinggi kuat tekan, maka kuat lentur juga akan meningkat [2]. Menurut Ahmad Syaifudin, 2015 antara kuat lentur dan kuat tarik belah beton serat baik tipe RC 80/60 BN maupun tipe RC 65/35 BN memiliki korelasi poritif, semakin besar nilai kuat lentur semakin besar nilai kuat tarik belahnya [3]

\section{TINJAUAN PUSTAKA}

\subsection{Material Pembentukan Beton}

Beton yang digunakan sebagai struktur sebagai struktur dalam konstruksi teknik sipil dapat dimanfaatkan untuk banyak hal seperti untuk bangunan pondasi, kolom, balok, pelat lantai. Dalam teknik sipil hidro, beton yang digunakan untuk bangunan air seperti bendungan, saluran dan drainase. Beton merupakan fungsi dari bahan penyusun yang terdiri bahan semen hidrolik (Porlantd Sement), agregat kasar, agregat halus, air, dan bahan tambah (admixture atau additive) [4] 


\subsection{Bahan Tambahan}

Bahan tambah (admixture) adalah suatu bahan berupa bubuk atau cairan, yang ditambahkan ke dalam campuran adukan beton selama pengadukan, dengan tujuan untuk mengubah sifat adukan atau betonnya. Berdasarkan ACI (American Concrete Institute), bahan tambah adalah material selain air, agregat dan semen hidrolik yang dicampurkan dalam beton atau sika yang ditambahkan sebelum atau selama pengadukan berlangsung. Penambahan bahan tambah dalam sebuah campuran beton atau sika tidak mengubah komposisi yang besar dari bahan lainnya, karena penggunaan bahan tambah ini cendurung merupakan pengganti atau susbtitusi dari dalam campuran beton itu sendiri. Karena tujuannya memperbaiki atau mengubah sifat dan karekteristik tertentu dari beton itu atau sika yang akan dihasilkan, maka kecenderungan perubahan komposisi dalam berat volume tidak terasa secara langsung di bandingkan dengan komposisi awal beton tanpa bahan tambah [14]

\subsection{Pengujian Slump}

Pengujian nilai Slump ialah salah satu cara untuk mengukur kecelakaan beton segar yang dipakai pula untuk memperkirakan tingkat kemudahan dalam pengerjaannya. dalam pelaksanaannya nilai Slump untuk berbagai pekerjaan pembetonan harus disesuaikan dengan syarat yang sesuai dengan pemakaiannya [5]. Nilai slump beton segar pada berbagai macam pemakaian disajikan pada tabel berikut ini [6]

\begin{tabular}{cccc}
\multicolumn{4}{c}{ Tabel 1 Nilai Slump Beton Segar } \\
Pada Berbagai Macam Pemakaian \\
\hline No & \multicolumn{1}{c}{ Pemakaian } & $\begin{array}{l}\text { Maks } \\
(\mathrm{mm})\end{array}$ & $\begin{array}{c}\text { Min } \\
(\mathrm{mm})\end{array}$ \\
1 & $\begin{array}{l}\text { Dinding, Plat Pondasi, } \\
\text { dan pondasi telapak }\end{array}$ & 12,5 & 5 \\
2 & $\begin{array}{l}\text { Pondasi Telapak tidak } \\
\text { bertulang, kaison, dan } \\
\text { struktur di bawah } \\
\text { tanah }\end{array}$ & 9 & 2,5 \\
\hline
\end{tabular}

\begin{tabular}{llcc}
\hline 3 & Pelat, balok, kolom, & & \\
& dan dinding & 15 & 7,5 \\
4 & Pengerasan jalan & 7,5 & 5 \\
5 & $\begin{array}{l}\text { Pembetonan massal } \\
\text { (beton massa) }\end{array}$ & & \\
& & 7,5 & 2,5 \\
\hline
\end{tabular}

\subsection{Kuat Lentur Beton}

Kuat lentur beton adalah kemampuan balok beton yang diletakkan pada dua perletakan untuk menahan gaya dengan arah tegak lurus sumbuh benda uji yang diberikan kepadanya sampai benda uji patah, dinyatakan dalam mega pascal (Mpa) gaya persatuan luas [7]. Untuk pengujian dimana bidang patah terletak didaerah pusat (1/3 jarak titik perletakan bagian tengah), maka kuat lentur beton dihitung menurut persamaan sebagai berikut [7]:

$$
\sigma i=\frac{P \cdot L}{D \cdot h^{2}}
$$

Sedangkan Untuk pengujian dimana patahanya benda uji ada diluar pusat ( (1/3 jarak titik perletakan bagian tengah) dan jarak antara titik pusat dan titik patah kurang dari 5\% dari jarak antara titik perletakan maka kuat lentur beton dihitung menurut persamaan sebagai berikut [7] :

$$
\sigma b m=\frac{r \cdot a}{b \cdot{ }^{a}}
$$

\footnotetext{
Dengan :
$\sigma i=$ Kuat lentur beton, $\mathrm{kg} / \mathrm{C}^{2}$
$\mathrm{P}=$ Beban yang terbaca pada alat uji dalam Kn di jadikan $(\mathrm{kg})$
$\mathrm{L}=$ Jarak antara dua perletakan $(\mathrm{cm})$
$\mathrm{b}=$ Lebar Melintang arah horizontal $(\mathrm{cm})$
$\mathrm{h}=$ Lebar Melintang arah vertikal $(\mathrm{cm})$

$\mathrm{a}=$ jarak Rata rata antara tampang melintang patah dan tumpuan yang terdekat, diukur pada temapt pada sudut bentang $(\mathrm{cm})$
} 


\section{METHODOLOGI}

\subsection{Lokasi dan Bahan Penelitian}

Lokasi penelitian adalah di Laboratorium Bidang Pengujian, Peralatandan BMD (Laboratorium) di Dinas Pekerjaan Umum Bina Marga dan Tata Ruang ProvinsiSumatera Selatan dan bahan yang digunakan dalam penelitian ini adalah :

1. Portland Semen adalah merek Semen Baturaja

2. Agregat kasar yang digunakan adalah batu pecah $19.00 \mathrm{~mm}$ dan $37.50 \mathrm{~mm}$ ex Merak

3. Agregat halus yang digunakan adalah pasir ex Tanjung Raja

4. Air PDAM Tirta Musi

5. Bahan Tambahan yang digunakan adalah Sika Concrete Refair Mortar sebagai pengganti semen.

\subsection{Ruang Lingkup Penelitian}

Ruang Lingkup Penelitian adalah :

1. Pemeriksaan karakteristik agregat halus dan kasr meliputi : pengujian berat jenis dan penyerapan air agregat kasar [8], pengujian berat jenis dan pengujian penyerapan air agregat halus [9], pengujian analisa saringan agregat halus dan kasar [10], pengujian kadar air agregat [11].

2. Pembuatan rencana campuran beton normal [12]

3. Pengujian Slump beton [5]

4. Pengujian kuat lentur beton [7]

5. Mutu beton yang dibuat adalah beton K 300

6. Penambahan Sika Concrete Refair Mortar sebesar 5\%, 10\%, 15\% dan 20\% dari berat semen yang digunakan untuk setiap karakteristik beton.

7. Pengujian kuat lentur beton dilakukan pada umur beton 28 hari.

\section{HASIL DAN PEMBAHASAN}

\subsection{Hasil Pengujian Agregat Halus dan Kasar}

Hasil pengujian karakteristik agregat halus dan kasar disajikan pada tabel 2.
Tabel 2 Nilai Karakteristik

Agregat Halus dan Kasar

\begin{tabular}{|c|c|c|c|}
\hline \multirow[b]{2}{*}{$\begin{array}{c}\text { Jenis } \\
\text { Pengujian }\end{array}$} & \multicolumn{3}{|c|}{ Nilai } \\
\hline & Pasir & $\begin{array}{l}\text { Split } \\
3 / 4 \text { inch }\end{array}$ & $\begin{array}{c}\text { Split } \\
1 \frac{1}{2} \text { inchi }\end{array}$ \\
\hline 1.Analisa & & & \\
\hline Saringan & & & \\
\hline $36.10\left(1^{1} / 2^{\prime \prime}\right)$ & - & - & 100 \\
\hline 25.40(1'’) & - & 100 & 52,10 \\
\hline 19.10(3/4'’) & - & 58,16 & 13,61 \\
\hline $9,25\left(3 / 8^{\prime \prime}\right)$ & 100 & 32,18 & 0,00 \\
\hline \#4 & 99,26 & 0,00 & - \\
\hline \#8 & 96,56 & - & - \\
\hline \#16 & 84,20 & - & - \\
\hline \#30 & 48,12 & - & - \\
\hline \#50 & 13,12 & - & - \\
\hline \#100 & 2,84 & - & - \\
\hline \#200 & 0,38 & - & - \\
\hline 2.Modulus & & & \\
\hline $\begin{array}{l}\text { Kehalusan } \\
\text { 3.Berat Isi : }\end{array}$ & 2,56 & 7,00 & 7,86 \\
\hline Lepas & 1,346 & 1,341 & 1,320 \\
\hline Padat & 1,442 & 1,473 & 1,401 \\
\hline $\begin{array}{l}\text { 4.Berat Jenis } \\
\text { dasar jenuh } \\
\text { kering } \\
\text { permukaan }\end{array}$ & 2,61 & 2,58 & 2,59 \\
\hline $\begin{array}{l}\text { 5.penyerapan } \\
(\%)\end{array}$ & 2,72 & 2,30 & 2,16 \\
\hline $\begin{array}{l}\text { 6.Kotoran } \\
\text { organic }\end{array}$ & No.3 & - & - \\
\hline $\begin{array}{l}\text { 7.Lewat } \\
\text { saringan No. }\end{array}$ & & - & \\
\hline $\begin{array}{l}200 \text { kadar } \\
\text { lumpur }\end{array}$ & 2,35 & & \\
\hline $\begin{array}{l}\text { 8.keausan } \\
(\%)\end{array}$ & - & 23,19 & 23,19 \\
\hline
\end{tabular}

\subsection{Komposisi Campuran Beton}

Kebetuhan material beton dengan menggunakan metode SNI 03-2834-2000 disajikan pada tabel 3.

Tabel 3. Kebutuhan Material untuk

Masing-masing Karakteristik Beton

\begin{tabular}{clc}
\hline No & \multicolumn{1}{c}{ Jenis Material } & $\begin{array}{c}\text { Kebutuhan } \\
\text { Material } \\
\text { Untuk } 1 \mathrm{M}^{3} \\
\text { Beton }\end{array}$ \\
\hline 1 & Semen & $451 \mathrm{~kg}$ \\
2 & Pasir & $617 \mathrm{~kg}$ \\
3 & Split Ukuran ${ }^{3 / 4}$ inchi & $531 \mathrm{~kg}$ \\
\hline
\end{tabular}




\begin{tabular}{clc}
\hline 4 & $\begin{array}{l}(19,00 \mathrm{~mm}) \\
\text { Split ukuran 1/2 inchi } \\
(37,50 \mathrm{~mm})\end{array}$ & $566 \mathrm{~kg}$ \\
5 & $\begin{array}{l}\text { Air PDAM } \\
\text { Sika Concrete Refair }\end{array}$ & $1,51 \mathrm{ltr}$ \\
& $\begin{array}{l}\text { Mortar 5\% } \\
\text { Sika Concrete Refair }\end{array}$ & $2,192 \mathrm{~kg}$ \\
8 & $\begin{array}{l}\text { Mortar 10\% } \\
\text { Sika Concrete Refair } \\
\text { Mortar 15\% }\end{array}$ & $3,288 \mathrm{~kg}$ \\
9 & $\begin{array}{l}\text { Sika Concrete Refair } \\
\text { Mortar 20\% }\end{array}$ & $4,384 \mathrm{~kg}$ \\
\hline
\end{tabular}

\subsection{Nilai Slump}

Pengujian nilai Slump dilakukan pada setiap campuran beton, hasil pengujian slump beton pada setiap campuran disajikan pada tabel 4 .

\section{Tabel 4 Nilai Slump Berbagai Variasi}

\begin{tabular}{clc}
\hline No & \multicolumn{1}{c}{ Jenis Beton } & $\begin{array}{c}\text { Nilai } \\
\text { Slump } \\
\text { (mm) }\end{array}$ \\
\hline 1 & $\begin{array}{l}\text { Beton Tanpa Penambah Sika } \\
\text { Concrete Refair Mortar }\end{array}$ & 80 \\
2 & $\begin{array}{l}\text { Beton dengan Penambah 5\% } \\
\text { Sika Concrete Refair Mortar } \\
\text { Beton dengan Penambah 10\% }\end{array}$ & 68 \\
3 & 67 \\
& $\begin{array}{l}\text { Sika Concrete Refair Mortar } \\
\text { Beton dengan Penambah 15\% } \\
\text { Sika Concrete Refair Mortar } \\
\text { Beton dengan Penambah 20\% } \\
\text { Sika Concrete Refair Mortar }\end{array}$ & 62 \\
\hline
\end{tabular}

\subsection{Hasil Pengujian Kuat Lentur}

Hasil pengujian kuat lentur beton karakteristik setiap campuran dan setelah dihitung disajikan dalam tabel 5 dan 6 .
Tabel 5 Deviasi Standar (S) Beton Umur 28 Hari

\begin{tabular}{|c|c|c|}
\hline No & Jenis Beton & $\begin{array}{l}\text { Deviasi } \\
\text { Standar } \\
\left(\mathrm{kg} / \mathrm{cm}^{2}\right)\end{array}$ \\
\hline 1 & $\begin{array}{lr}\text { Beton } & \text { Tanpa } \\
\text { Penambahan } & \text { Sika }\end{array}$ & 0,56 \\
\hline 2 & $\begin{array}{l}\text { Concrete Refair Mortar } \\
\text { Beton Penambahan } 5 \% \\
\text { Sika Concrete Refair } \\
\text { Mortar }\end{array}$ & 2,20 \\
\hline 3 & $\begin{array}{l}\text { Beton Penambahan } 10 \% \\
\text { Sika Concrete Refair } \\
\text { Mortar }\end{array}$ & 2,85 \\
\hline 4 & $\begin{array}{l}\text { Beton Penambahan } 15 \% \\
\text { Sika Concrete Refair } \\
\text { Mortar }\end{array}$ & 4,25 \\
\hline 5 & $\begin{array}{l}\text { Beton Penambahan } 20 \% \\
\text { Sika Concrete Refair } \\
\text { Mortar }\end{array}$ & 1,28 \\
\hline
\end{tabular}

Tabel 6 Kuat Lentur Beton Umur 28 Hari

\begin{tabular}{|c|c|c|}
\hline No & Jenis Beton & $\begin{array}{l}\text { Kuat Lentur } \\
\text { Beton } \\
\text { Karakteristik } \\
\left(\mathrm{kg} / \mathrm{cm}^{2}\right)\end{array}$ \\
\hline 1 & $\begin{array}{lr}\text { Beton } & \text { Tanpa } \\
\text { Penambahan } & \text { Sika } \\
\text { Concrete } & \text { Refair } \\
\text { Mortar }\end{array}$ & 52,33 \\
\hline 2 & $\begin{array}{l}\text { Beton Penambahan } \\
5 \% \text { Sika Concrete } \\
\text { Refair Mortar }\end{array}$ & 57,87 \\
\hline 3 & $\begin{array}{l}\text { Beton Penambahan } \\
10 \% \text { Sika Concrete } \\
\text { Refair Mortar }\end{array}$ & 53,84 \\
\hline 4 & $\begin{array}{l}\text { Beton } \\
\text { Penambahan } 15 \% \\
\text { Sikg Concrete }\end{array}$ & 53,34 \\
\hline 5 & $\begin{array}{l}\text { Refair Mortar } \\
\text { Beton Penambahan } \\
20 \% \text { Sika Concrete } \\
\text { Refair Mortar }\end{array}$ & 46,80 \\
\hline
\end{tabular}


4.5. Grafik Hasil Uji Kuat Lentur

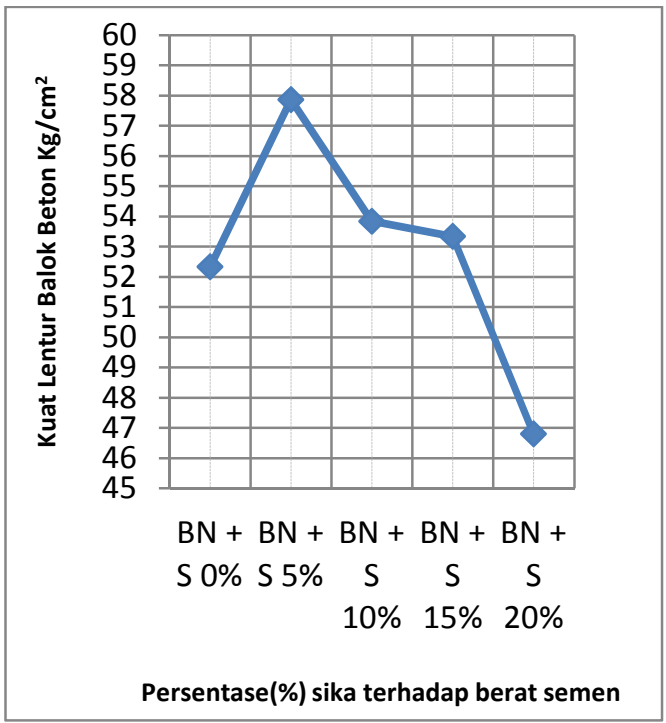

\section{KESIMPULAN}

Dari hasil penelitian ini dapat disimpulkan sebagai berikut :

1. Kuat lentur beton tanpa penambahan Sika Concrete Refair Mortar utama sebesar $53,84 \mathrm{~kg} / \mathrm{cm}^{2}$

2. Kuat tekan beton K 300 terbesar adalah dengan penambahan Sika Concrete Refair Mortar 5\% dengan nilai kuat tekan $57,87 \mathrm{~kg} / \mathrm{cm}^{2}$.

\section{DAFTAR PUSTAKA}

[1] Ali Asroni, 2010, Balok dan Pelat Beton Beton Bertulang, Penerbit Graha Ilmu Yogyakarta, Cetakan Pertama.

[2] Yohanes Trian Dady, M.D.J. Sumajouw, R.S. Windah 2015, Pengaruh Kuat Tekan Terhadap Kuat Lentur Balok Beton Bertulang, JURNAL SIPIL STATIK Vol 3 No. 5, Mei 2015 (341350) ISSN 2337-6732, pp 341-350

[3] Ahmad Syaifudin, Solihin As'ad, Sunarmasto 2015, Pengaruh Dosis, Aspek Rasio dan Distribusi Serat Terhadap Kuat Lentur dan Kuat Tarik Belah Beton berserat Baja, e-Jurnal MATRIK TEKNIK SIPIL, Juni 205, pp. 369-376

[4] Mulyono, Tri. 2003 Teknologi Beton Penerbit Andi Jakarta
[5] SNI 03-1972-1990 Metode Pengujian Slump Beton, Badan Standarisasi Nasional

[6] Peraturan Beton Bertulang Indonesia Tahun 1971 Dinas Pekrjaan Umum DPMB Bandung.

[7] SNI 4431:2011 Cara Pengujian Kuat Lentur Beton Dengan Dua Titik Peme bebanan, Badan Standarisasi Nasiona ICS 90.100.30.

[8] SNI 1969:2008 Cara Uji Berat Jenis dan Penyerapan Air Agregat Kasar, Badan Standarisasi Nasional

[9] SNI 03-1970-2008 Cara Uji Berat Jenis dan Penyerapan Air Agregat Halus, Badan Standarisasi Nasional

[10] SNI 03-1974-1990 Metode Pengujian Analisa Saringan Agregat Halus dan Kasar, Badan Standarisasi Nasional

[11] SNI 03-1971-1990 Metode Pengujian Kadar Air Agregat, Badan Standarisasi Nasional

[12] SNI 03-2834-2000 Tata Cara Pembuatan Rencana Campuran Beton, Normal, Badan Standarisasi Nasional

[13] http://idn.sika.com/in/group/tentangkami/katalog-sikaindonesia.html\#sthash.tvwDocHj.dpuf

[14] http://khedanta.wordpress.com/2012/06/1 1/bahan-tamba-untuk-campuran-beton 